\title{
ANALYSIS OF THE INTRA-CITY VARIATION OF URBAN HEAT ISLAND AND ITS RELATION TO LAND SURFACE/COVER PARAMETERS
}

\author{
D. Gerçek ${ }^{a}$ *, İ.T. Güven ${ }^{\text {a }}$ İ.Ç. Oktay ${ }^{\text {b }}$ \\ ${ }^{a}$ Kocaeli University, Faculty of Architecture and Design, 41300, İzmit, Kocaeli, Turkey - (denizger, talihguven)@ gmail.com \\ ${ }^{\mathrm{b}}$ Kocaeli Metropolitan Municipality, İzmit, Kocaeli, Turkey - caglaroktay @ kocaeli.bel.tr
}

Commission VI, WG VI/4

KEYWORDS: Thermal Remote Sensing, microclimate, Urban Heat Island

\begin{abstract}
:
Along with urbanization, sealing of vegetated land and evaporation surfaces by impermeable materials, lead to changes in urban climate. This phenomenon is observed as temperatures several degrees higher in densely urbanized areas compared to the rural land at the urban fringe particularly at nights, so-called Urban Heat Island. Urban Heat Island (UHI) effect is related with urban form, pattern and building materials so far as it is associated with meteorological conditions, air pollution, excess heat from cooling. UHI effect has negative influences on human health, as well as other environmental problems such as higher energy demand, air pollution, and water shortage.

Urban Heat Island (UHI) effect has long been studied by observations of air temperature from thermometers. However, with the advent and proliferation of remote sensing technology, synoptic coverage and better representations of spatial variation of surface temperature became possible. This has opened new avenues for the observation capabilities and research of UHIs.

In this study, 'UHI effect and its relation to factors that cause it' is explored for İzmit city which has been subject to excess urbanization and industrialization during the past decades. Spatial distribution and variation of UHI effect in İzmit is analysed using Landsat 8 and ASTER day \& night images of 2015 summer. Surface temperature data derived from thermal bands of the images were analysed for UHI effect. Higher temperatures were classified into 4 grades of UHIs and mapped both for day and night.

Inadequate urban form, pattern, density, high buildings and paved surfaces at the expanse of soil ground and vegetation cover are the main factors that cause microclimates giving rise to spatial variations in temperatures across cities. These factors quantified as land surface/cover parameters for the study include vegetation index (NDVI), imperviousness (NDISI), albedo, solar insolation, Sky View Factor (SVF), building envelope, distance to sea, and traffic space density. These parameters that cause variation in intra-city temperatures were evaluated for their relationship with different grades of UHIs. Zonal statistics of UHI classes and variations in average value of parameters were interpreted. The outcomes that highlight local temperature peaks are proposed to the attention of the decision makers for mitigation of Urban Heat Island effect in the city at local and neighbourhood scale.
\end{abstract}

\section{INTRODUCTION}

Urban growth and sprawl have drastically altered the biophysical environment with the most evident change occurring as the replacement of soil and vegetation cover with impervious urban materials, such as concrete, asphalt, and building materials, which affect the albedo, evapotranspiration and runoff characteristics of the land surface. The direct impact of this is the rise of urban temperatures leading to the formation of the Urban Heat Island (UHI) (Lo and Quattrochi, 2003; Gluch et al. 2006).

Climate change projections notify that the heat waves such as those took place in 2003 and 2006 in Europe will occur more often and with a higher intensity in future than today (Fischer and Schär, 2010; Rahmstorf and Coumou, 2011). Even though the rural and the urban lands are exposed to these regional climate events to the same extent, influences exaggerate locally where Urban Heat Island phenomenon is effective.

* Corresponding author
Along with the climate change, urbanization is also expected to grow in the next decades. Amount of people who live in cities increase each year. In the year 2050, urban population residing in urban sprawls of developing countries is expected to double in number (United Nations, 2014). To accommodate urban population growth, urban sprawl enlarges and densifies leading to rapid changes in land use patterns with adverse consequences affecting environmental and social life in cities. Therefore, Urban Heat Island (UHI) as the most obvious fact about urban climate has increasingly become one of the most prominent faces of the climate change-related challenges faced by society (Mayor of London, 2006).

The study area, İzmit, with its proximate location to İstanbul, strong transportation connections, suitable topography and climate, has drastically transformed into an industrial region since 1960's with Turkish heavy industrial leap. Rapid industrialization severely increased population and constituted the dense and irregular city form that lacks a well-organized plan. Today, there is still a strong trend of urbanization where the rate of increase in population is twice the Turkey's average 
according to the 2011 census (URL-1). Together with industrial development, the landscape has changed significantly. Land use/cover change is an important indicator for assessment of climate change in İzmit where Urban Heat Island phenomenon can also be critical.

The climatological description of İzmit, similar to most of the big cities, is made based on a few meteorological stations located in the city center and not representative of the whole city. Therefore, intra-urban variations of Urban Heat Island effect in İzmit is explored taking advantage of synoptic view of satellite images. Landsat 8 day and ASTER night satellite images were used to map Urban Heat Island effect quantified by Land Surface Temperatures (LST) throughout the city. Land surface temperatures were classified into four grades converging to equal count of pixels per class. These classes were than evaluated for their relationship with factors that generate UHI effect, quantified as 'land surface/cover parameters' to understand the relative impact of these factors to the intensity of the Urban Heat Island effect.

To ensure an effective and coherent development of adaptation strategies aimed at improvement of the urban environment through mitigation of Urban Heat Island effect, a better understanding of the spatial and temporal intra-city variability of UHI and the influence of land surface parameters therein is needed.

\section{DATA AND METHODS}

\subsection{Study Area}

İzmit city is located at the İzmit Bay of the Marmara Sea, in the Northwest of Turkey (Figure 1). The city is the industrial heart of Turkey with ports connected to major highways and railway. İzmit is situated on the main transportation corridors connecting İstanbul and the Capital city Ankara. The city covers approximately $18,71 \mathrm{~km}^{2}$ of land surface and has about 350.000 inhabitants (URL-2). Most of the area lies several meters above sea level, and is on a sandy plain. The topography gets rough in the northern parts of the city which limits the settlement activities and leads to densification in the city center. Climate of the study area can be assigned to the category of a transitional climatic zone between Mediterranean and the humid climate of Blacksea, with the Mediterranean climate influences being dominant in summers (URL-3). Lowest and highest temperatures observed are $3.3^{\circ} \mathrm{C}$ in January and $29.6^{\circ} \mathrm{C}$ in August respectively (URL-4).

Higher temperatures of urban central areas compared to outlying rural surroundings particularly at night; is what constitutes evidence to an Urban Heat Island (UHI). Different cooling rates between urban areas and their surrounding rural land identifies the severity of UHI effect in a city and is described as UHI intensity $(\Delta \mathrm{T})=\mathrm{T}_{\text {urban }}-\mathrm{T}_{\text {rural }}$ (Oke, 1982). According to two fixed meteorological stations in the city, first being near the city center and second in the rural fringe, maximum heat island development $(\max (\Delta \mathrm{T}))$ is observed as $4 \mathrm{C}^{\circ}$ at $02: 00$ (Figure 2) that points out to an obvious sign of UHI phenomenon in İzmit.

\subsection{Surface Temperature and UHIs}

Land Surface Temperature (LST) is one of the most important parameters in the physical processes of surface energy balance (Anderson et al., 2008) and it modulates the air temperature of the lowest layers of the urban atmosphere (Vogt and Oke,
2003). Therefore, knowledge of the LST is of fundamental importance in many applications including urban climate among others (Li et al., 2013).

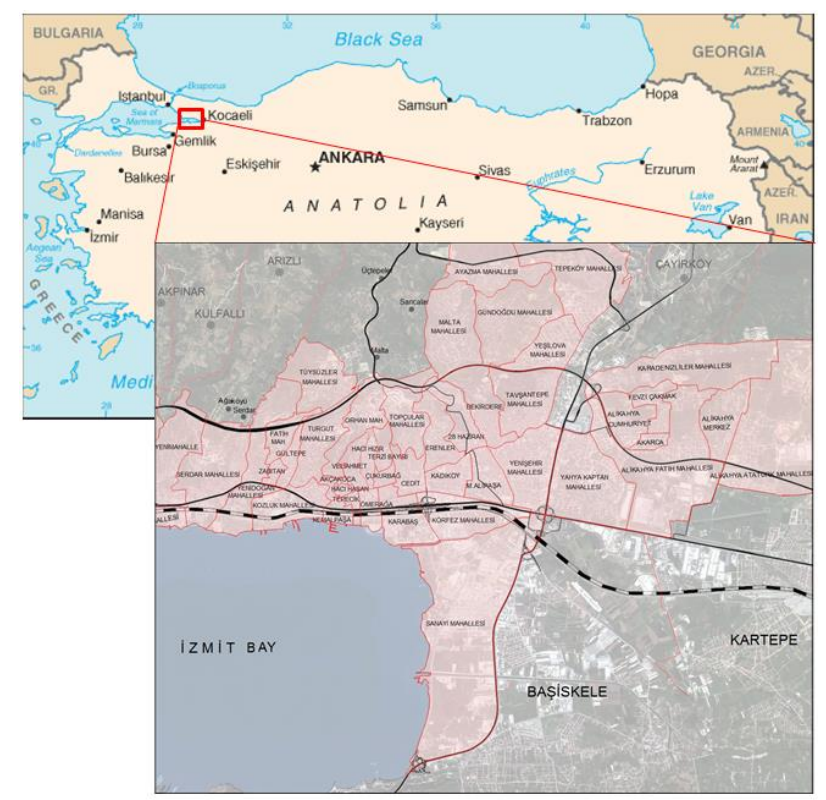

Figure 1. Location of İzmit city, Kocaeli, Turkey

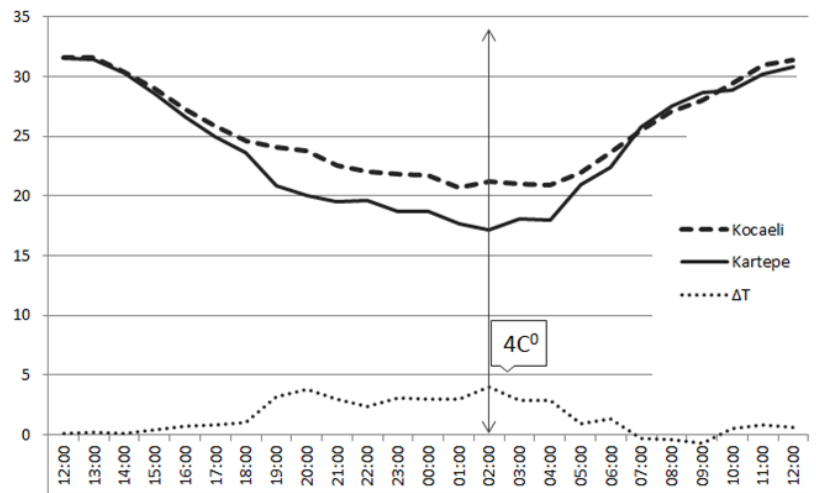

Figure 2. Diurnal evolution of the

Urban Heat Island intensity $(\Delta \mathrm{T})$ for İzmit from two fixed stations Kocaeli (urban), Kartepe (rural)

2.2.1 Landsat 8 Day Surface Temperatures and UHI: In this study, Radiative Transfer Equation (RTE) was used to extract Surface Temperature out of Landsat 8 thermal bands acquired on August 30, 2015. A four phased transformation was carried out to reach surface kinetic temperature values from raw DN values of image cells;

i) DN values were converted to Radiance using offset (bias) and gain values.

ii) Emissivity $(\varepsilon)$ values for each cell were obtained. Accordingly, NDVI which is closely related with emissivity (Brunsell and Gilles, 2002) is used as thresholds to designate emissivity values as suggested by Sobrino et al. (2008).

iii) Atmospheric effects including atmospheric transmission $(\tau)$, upwelling atmospheric radiation $\left(S^{\uparrow}\right)$ and downwelling atmospheric radiation $\left(S_{\downarrow}\right)$ were derived using Atmospheric Correction Parameter Calculator (URL-5) that is based on MODTRAN Radiative Transfer code modelling from National Centers for Environmental Prediction (NCEP) global atmospheric profiles database. 
Radiative Transfer Equation (RTE) taking into account $(\varepsilon), \tau, S_{\downarrow}$ and $S^{\uparrow}(1)$ is transformed through applying inverse of the Plank equation (2) to derive Surface Temperature.

$\mathrm{L}_{\lambda^{\circ}}=\left[\varepsilon \mathrm{B}_{\mathrm{Ts}}+1(1-\varepsilon) \mathrm{S}_{\downarrow}\right] \tau+\mathrm{S}^{\uparrow}$ where;

$L_{\lambda}=$ Thermal radiance at sensor

$\mathrm{B}_{\mathrm{Ts}}=$ 'blackbody radiance' (Plank's law)

$T_{S}=\frac{C_{2}}{\lambda \ln \left\{\frac{C_{1}}{\lambda^{5}\left[\frac{L_{\lambda^{-}} S^{\uparrow}-\tau(1-\varepsilon) S_{\downarrow}}{\tau \varepsilon}\right]}\right\}+1}$

where;

Ts $=$ Land surface temperature

$\varepsilon=$ Land surface emissivity

$\tau=$ Atmospheric transmissivity

$S^{\uparrow}=$ Upwelling atmospheric radiance

$S_{\downarrow}=$ Downwelling atmospheric radiance

$\lambda=$ effective band wavelenght

constants: $\quad \mathrm{C}_{1}=1.191 \times 108 \mathrm{~W} \mu \mathrm{m} 4 \mathrm{sr}-1 \quad \mathrm{~m}-2$,

$\mathrm{C}_{2}=1.439 \times 104 \mu \mathrm{m} \cdot \mathrm{K}$

The calculated temperature values in Kelvin were then converted to degree Celsius $\left({ }^{0} \mathrm{C}\right)$.

The Land surface temperature (Ts) of İzmit city calculated using the Landsat 8 images were classified into 4 classes that depict the LST distribution pattern in the city as illustrated in Figure 3. The highest temperature value class assigned with orange colour indicates the regions with highest LSTs; hence can be considered as the possible UHI formations in daytime in the city. The lowest temperature class assigned with dark blue color indicates the sea, dense vegetation and green valleys in the northern fringe.

2.2.2 ASTER night surface Temperatures and UHI: Impervious surfaces store thermal energy during the day and continue to emit it at night. The heat stress is kept at high levels for hours after sunset and nocturnal temperatures of typical surfaces do not cool down enough. This is the major reason why UHI demonstrates the maximum intensity 3-5 hours after sunset; hence is the key indicator to UHI (Oke, 1997). Therefore, surface night temperature is of critical importance for UHI studies.

\subsection{Land Surface/Cover Parameters}

Urbanization and urban form is known to have a major role in forming UHIs. Building density and spatial organization, building height, paved surfaces, amount of vegetative cover, traffic density as well as other natural factors such as being exposed to sun, being close to water bodies all create variations in intra-urban climate and form different intensities of UHI within the urban environment.

In this study, ASTER night time images acquired on August 31, 2015 were used. The Kinetic surface temperature product that was gathered through temperature emissivity separation method (TES) (Gillespie et al., 1999) were readily used after geometric correction and Kelvin to Degree Celsius conversion.

The nocturnal land surface temperature (Ts) of İzmit from ASTER Kinetic surface temperature product were classified into 4 classes that depict the LST distribution pattern in the city as illustrated in Figure 4.

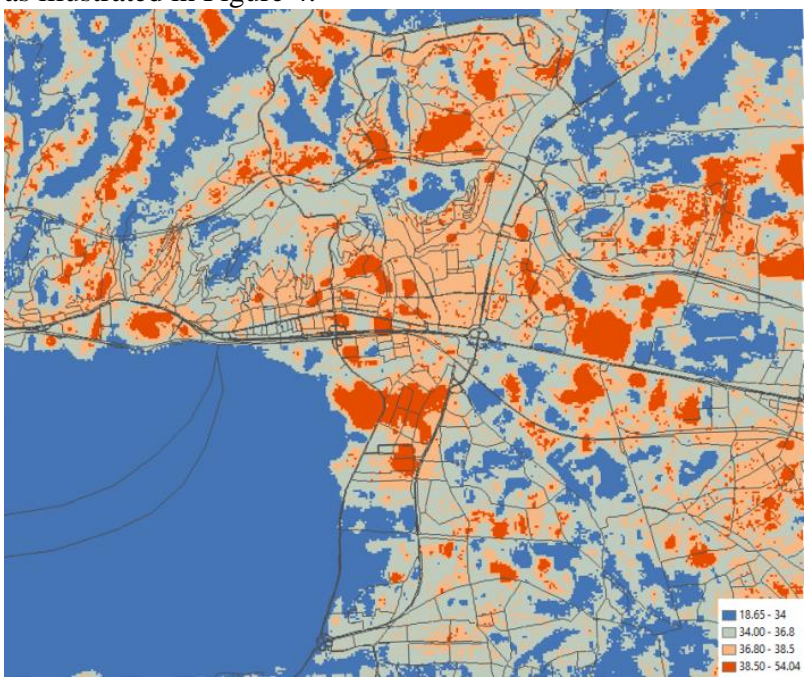

Figure 3. Distribution of land surface day temperature in İzmit city

The highest temperature value class assigned with orange color indicates the regions with highest LSTs and correspond mainly to urban traffic and dense settlements; hence can be considered as the possible UHI formations in nighttime in the city. The lowest temperature class assigned with dark blue color indicates dense vegetation and green valleys in the northern fringe.

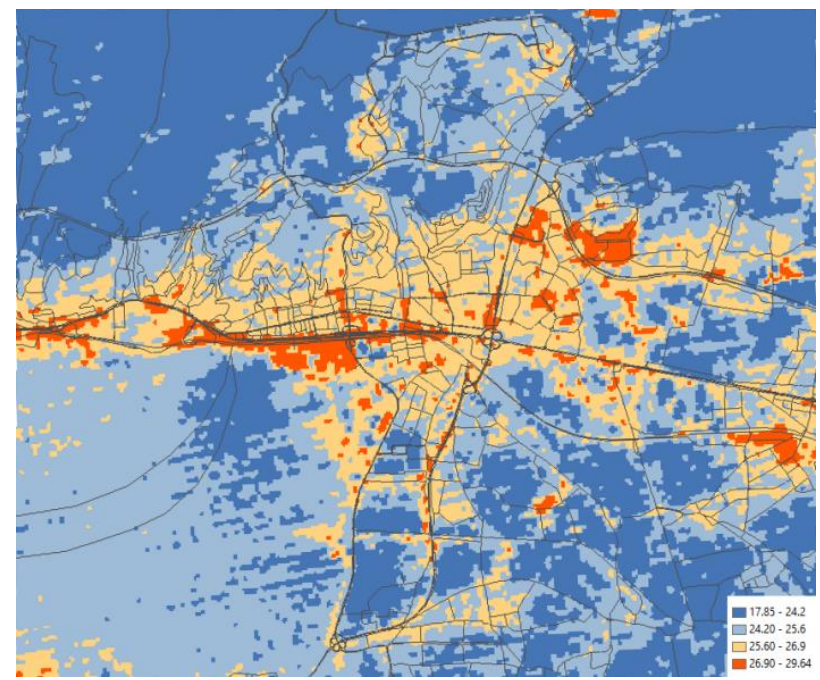

Figure 4. Distribution of land surface night temperature in İzmit city

In this section of the study, land surface/cover parameters that quantify above mentioned factors are generated and the relation between land surface/cover parameters and the daytime and nighttime surface temperatures are investigated. Land surface parameters for İzmit city were quantified for standard mapping unit taken as Landsat spatial resolution $(30 \mathrm{~m})$ and mapped using image-based data, Digital Elevation Model (DEM), municipal GIS data and other sources of information. Land surface/cover parameters for the study include greenness (NDVI), Imperviousness (NDISI), albedo, solar insolation, Sky View Factor (SVF), building envelope, distance to sea, and traffic space density. The satellite image used for the analyses is the Landsat 8 daytime image acquired on August 30, 2015. 


\section{Greenness}

Vegetative cover causes heat loss during transpiration and blocks radiation from the sun beneath surfaces, hence is a reducing factor of UHI. Greenness is quantified by Normalized Difference Vegetation Index (NDVI) as in (3). Resultant map is depicted in Figure 5-a.

$$
\mathrm{NDVI}=(N I R-R e d) /(N I R+R e d)
$$

\section{Imperviousness}

Imperviousness indicate the extent to which the surface is covered by impervious materials such as stone, asphalt, concrete or sand and is quantified with Normalized Difference Impervious Surface Index (NDISI) as in (4). Resultant map is depicted in Figure 5-b.

$$
\mathrm{NDISI}=(S W I R 1-R e d) /(S W I R 1+R e d)
$$

\section{Albedo}

Albedo is the reflection of solar radiation at all reflective wavelengths by the surface. Higher albedos typically result in lower LSTs, where lower albedos result in higher LSTs due to absorption. Albedo from reflective bands is typically gathered as in the (5) (Liang, 2000). Resultant map is depicted in Figure 5 -c.

$$
\text { Albedo }=\frac{0.356 \rho_{2}+0.130 \rho_{3}+0.373 \rho_{4}+0.085 \rho_{5}+0.072 \rho_{7}-0.0018}{0.356+0.130+0.373+0.085+0.072}
$$

where;

$\rho_{1}$ denotes the bands of Landsat 8'nin 2, 3, 4, 5, 7

\section{Solar Insolation}

Solar insolation is a measure of how much energy from the sun is received by the surface based on date, time, coordinates and topography. It is formulated as in (6).

$$
\begin{aligned}
& \text { SI: } 255[\cos (90-Z) \sin (\alpha) \cos (\beta-A)+\sin (90-Z) \cos (\alpha)] \\
& \text { where; } \\
& \text { Z: zenith } \\
& \text { A: azimuth } \\
& \alpha: \text { slope } \\
& \beta \text { : aspect. }
\end{aligned}
$$

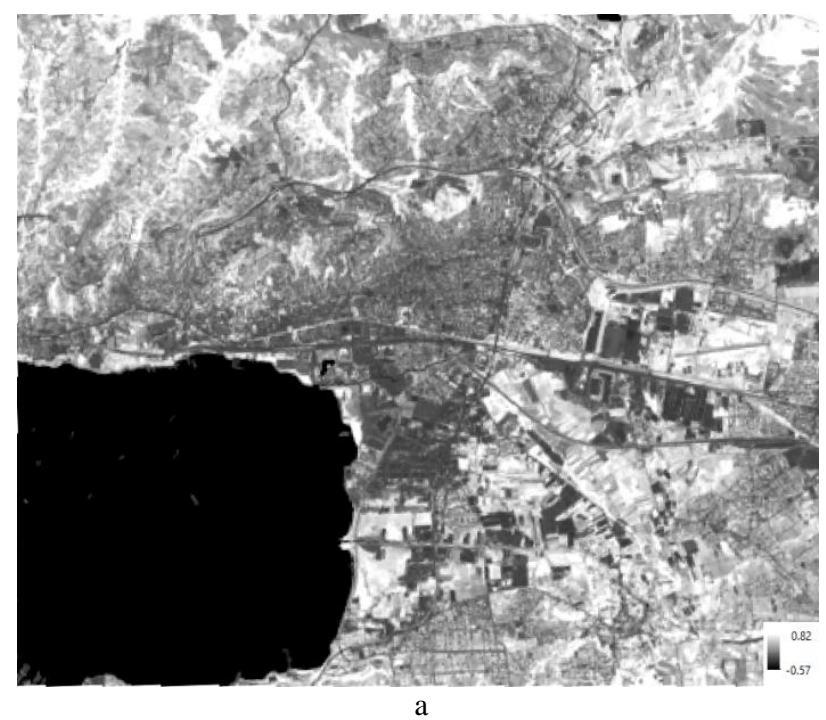

Sun zenith and azimuth angles for İzmit at the specific time the Landsat 8 image was taken (August 30,2015) is as below:

$$
\text { Z: } 57 ., 13^{\circ}, \mathrm{A}: 196.99^{\circ}(\mathrm{URL}-3)
$$

Resultant map is depicted in Figure 5-d.

\section{Sky View Factor (SVF)}

Sky-view factor indicates the level of exposure of the surface to the sky. Limited exposure to the sky due to building density results in a reduced ability to release heat stored during daytime. Surface model with building heights were produced from a fine DEM of $5 \mathrm{~m}$ spatial resolution and building footprint polygons with elevation obtained from Municipality dataset. A TIN is produced which is then transformed into a raster surface. The Sky View Factor (SVF) was calculated using the SVF Computation Code of SAGA from the elevation raster. Resultant map is depicted in Figure 5-e.

\section{Building Envelope}

The building envelope quantified by volumetric quantity of the buildings is an extension of the urban surface and indicates an increased exposure to solar radiation and an increased capacity to nocturnally emit heat that was stored during the day. Building envelope was calculated from the building footprint polygons and the building height information. Resultant map is depicted in Figure 5-f.

\section{Distance to Sea}

Proximity to water bodies usually has cooling effects on urban land surfaces. Therefore, this parameter was calculated as a contributing factor to UHI variability. Distance to sea is calculated using the coast line and sea is masked from the analyses. Resultant map is depicted in Figure 5-g.

\section{Traffic Space Density}

Traffic space density describes the density of city roads per unit area and is expected that this landuse is predominantly impervious and is antropogenetically heated by vehicles. Trafic space density is derived by running a spatial kernel function on the road network of different widths as weights. Resultant map is depicted in Figure 5-h.

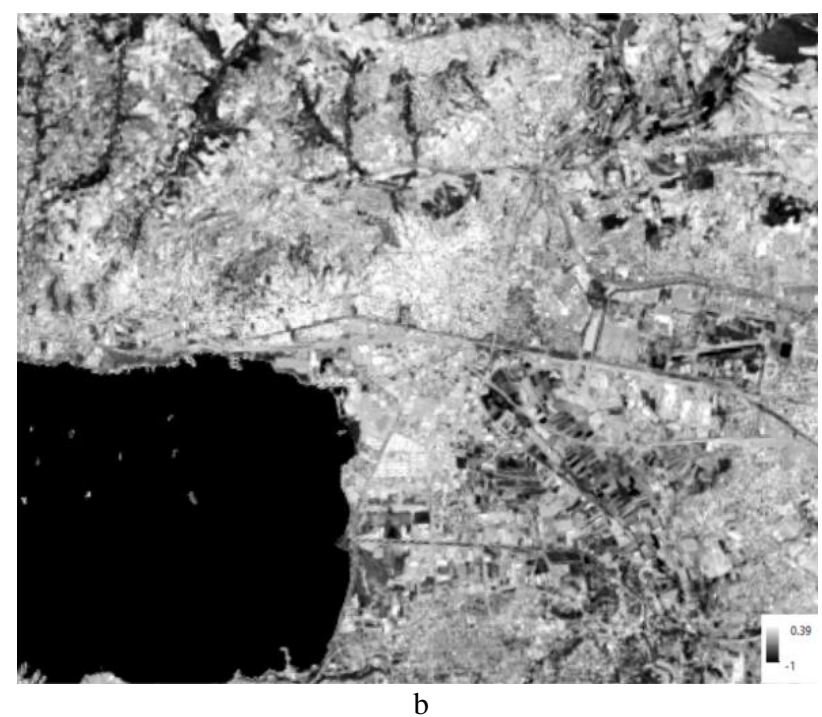



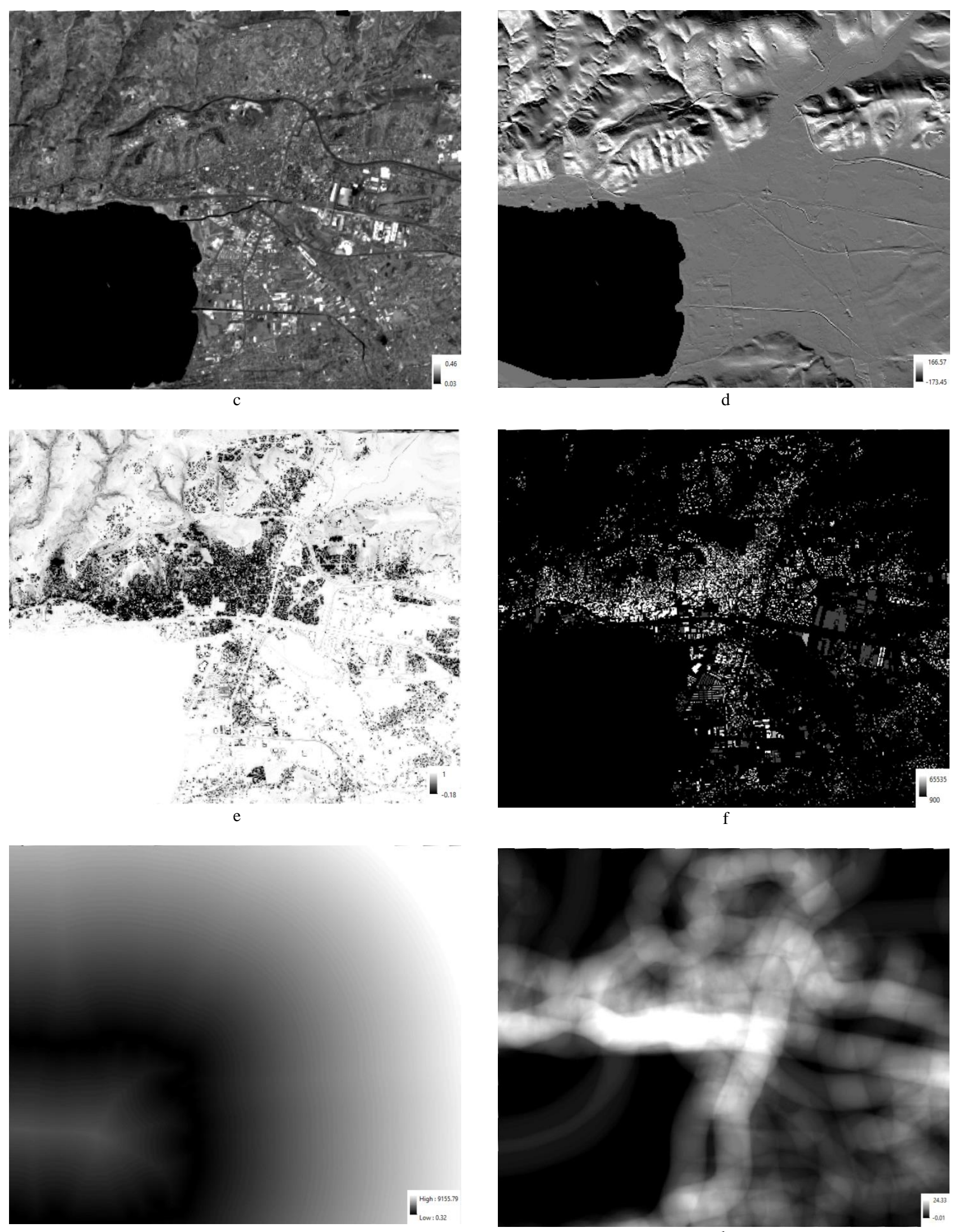

g

Figure 5. Land surface parameters for İzmit city 


\section{RESULTS AND CONCLUSIONS}

Variation of UHI within the city as four grades of land surface temperatures and land surface/cover parameters that contribute to UHI effect is analyzed through

(i) Zonal statistics of land surface/cover parameters per UHI grade (day \& night)

(ii) Range of surface temperature (day \& night) between the minimum and maximum value of the land surface/cover parameters

Zonal statistics of land surface/cover parameters for daytime UHI

Zonal statistics for each land surface parameter was calculated for each of the four grades of UHI. The mean values for daytime UHI is illustrated in Figure 6.

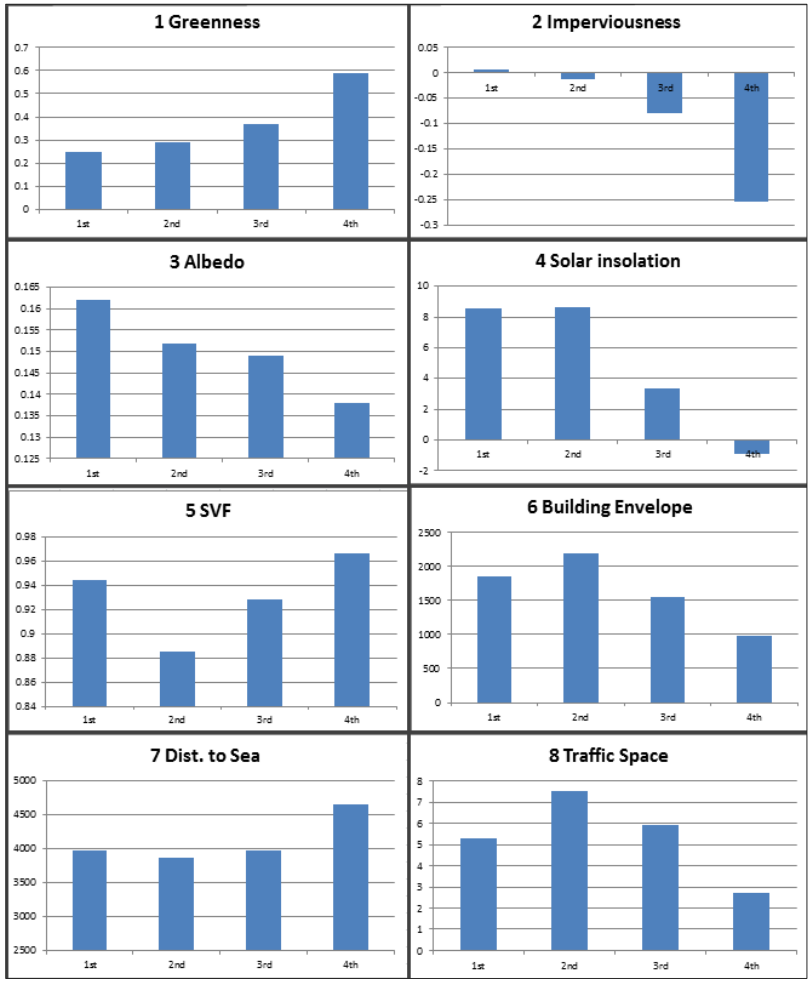

Figure 6. Land surface/cover parameters per UHI grade for Landsat daytime image

Parameters derived from Landsat image; greenness, imperviousness, and albedo portray a regular pattern of contribution to daytime UHI. Solar insolation that is mainly regulated by topography is alike. This signifies that the daytime UHI intensifies as greenness decrease, imperviousness, albedo and solar insolation increase. Among these outcomes, albedo conflicts with what is expected, as higher albedos supposedly lead to lower surface temperatures (Ts) in the study area. It is considered that stronger parameters like greenness or imperviousness have surpassed the effect of albedo. SVF and building envelope that describes the city form and density show that the UHI grade increase as the SVF decrease and building envelope increase, but with the exceptional first grade UHI. This typical pattern is also observed in traffic space density which is attributed to open, paved or bare surfaces with high $\mathrm{SVF}$, as well as low building envelope and less traffic space where the first grade daytime UHI is set. Distance to sea is not observed to have particular contribution to UHI.
Zonal statistics of land surface/cover parameters for nighttime $U H I$

The mean values of each parameter for daytime UHIs are illustrated in Figure 7.

Parameters derived from the images; greenness and imperviousness compared with nighttime UHIs show a pattern similar to that in daytime UHIs. Albedo and solar insolation that are related with radiation energy from the sun at daytime show little relevance to nighttime UHIs as expected. Nighttime UHI grade tend to increase with low SVF and high building envelope, but as for the daytime UHI, first grade nighttime shows an irregular pattern, this time attributed to urban traffic where first grade UHI is set. Distance to sea contribution is attributed to distance to city center that is located in close vicinity to sea side. The most prominent effect is observed as the traffic space density that has a strong relationship with the nighttime UHI.

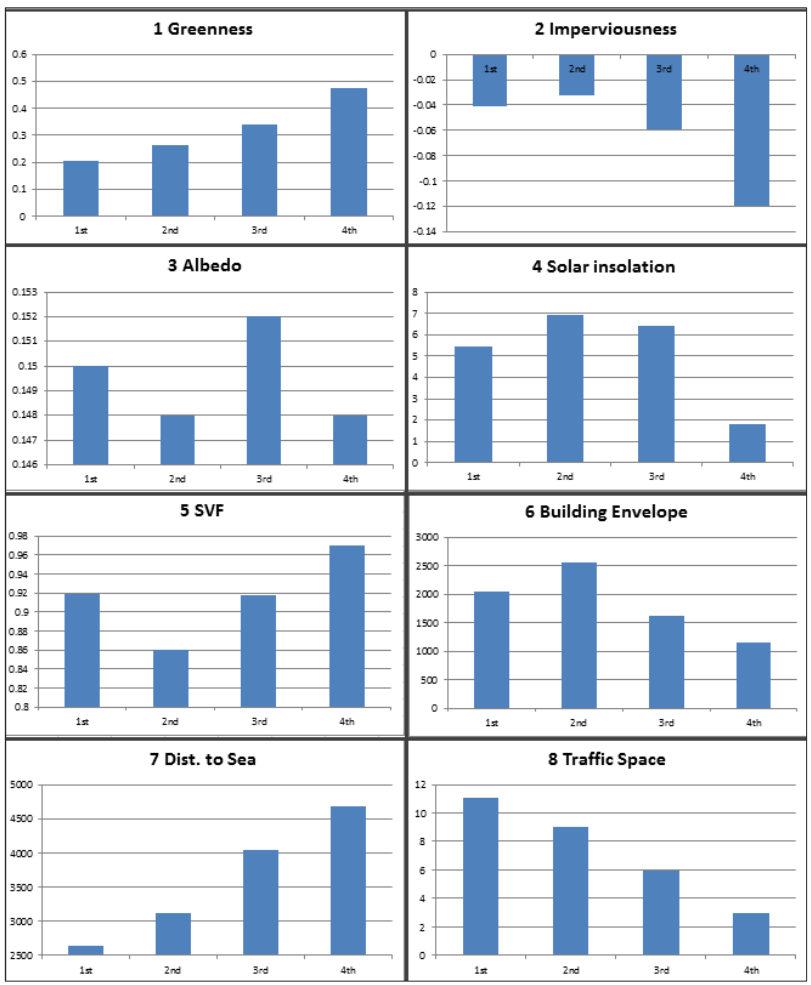

Figure 7. Land surface/cover parameters per UHI grade for ASTER nighttime image

Range of surface temperature for land surface/cover parameters

Surface temperatures that correspond to least and the greatest values of land surface parameters account for temperature ranges that is presumed as relative impact of the parameters to the UHI intensity represented as four grades. Larger ranges designate greater impact from the land surface/cover parameter where lower ranges designate minor impact. The results are depicted for both daytime and night time surface temperatures per parameter (Figure 8).

Highest ranges of temperatures are observed for parameters; greenness and imperviousness. Albedo and solar insolation has greater impact on daytime UHIs compared to night time UHIs. Highest temperatures occur in spaces where building density is very low or the space is open, paved, bare or large roofs for day time UHI, and traffic space for the night time UHI. 


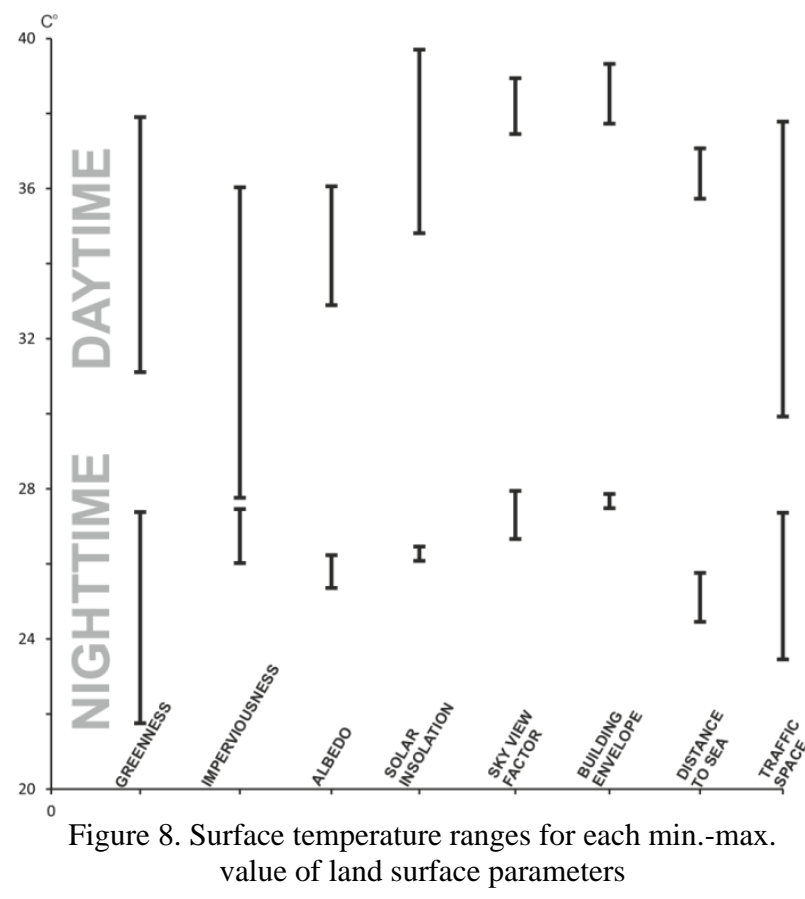

This is the main reason why SVF and building envelope parameters that are expected to be in strong relation especially with night time UHIs show little variation of surface temperature. Traffic space as an anthropogenic factor has a big impact on both daytime and night time UHIs.

\section{ACKNOWLEDGEMENTS}

Kocaeli Metropolitan Municipality is thanked for supporting this study.

\section{REFERENCES}

Anderson, M. C., Norman, J. M., Kustas, W. P., Houborg, R., Starks, P. J., \& Agam, N.(2008). A thermal-based remote sensing technique for routine mapping of land-surface carbon, water and energy fluxes from field to regional scales. Remote Sensing of Environment, 112, 4227-4241

Brunsell N.A., Gilles R., 2002. Incorporating Surface Emissivity into a Thermal Atmospheric Correction, Photogrammetric Engineering \& Remote Sensing, 68(12). pp. 1263-1269.

Fischer EM, Schär C., 2010. Consistent Geographical Patterns of Changes in Highimpact European Heatwaves, Nature Geoscience, 3, p 398-403

Gillespie A., Rokugawa S., Hook, S.J., Matsunaga, T., Kahle, A.B., 1999. ASTER Temperature/emissivity separation algorithm theoretical basis document, version 2.4 Washington, DC: NASA, Mar. 1999.

Gluch, R., A.D. Quattrochi, and J.C. Luvall, 2006. A multiscale approach to urban thermal analysis, Remote Sensing of Environment, 104(1):123-132.
Li Z-L., Tang B-H., Wu H., Ren H., Yan G., Wan Z., Trigo I.F., Sobrino J.A., 2013. Satellite-derived land surface temperature: Current status and perspectives, Remote Sensing of Environment, 131, s. 14-37.

Liang, S. 2000. "Narrowband to broadband conversions of land surface albedo I algorithms." Remote Sensing of Environment, 76, 213-238.

Lo, C. P. and D. A. Quattrochi, 2003, "Land-Use and LandCover Change, Urban Heat Island Phenomenon, and Health Implications, a Remote Sensing Approach," Photogrammetric Engineering and Remote Sensing, 69(9):1053-1063.

Mayor of London. London's urban heat island: a summary for decision makers. London: Greater London Authority, 2006.

Oke, T. R., 1997. Urban climates and global change, Applied climatology: principles and practice, A. Perry and R. Thompson (eds.), London, Routledge, 273-287.

Oke, T.R. 1982. The Energetic Basis of the Urban Heat Island. Quarterly Journal of the Royal Meteorological Society. 108:124

Rahmstorf, S., Coumou, D., 2011. Increase of extreme events in a warming world. Proc. Natl. Acad. Sci. 108, 17905-17909.

Sobrino J.A., Jiménez-Muñoz J.C., Sòria G., Romaguera M., Guanter L., Moreno J., Plaza A., Martínez P., 2008, Land SurfaceEmissivityRetrieval FromDifferent VNIR and TIR Sensors, IEEE Transactions on Geoscienceand Remote Sensing, 46(2), pp. 316-327

United Nations, 2014.United Nations: world urbanization prospects: the 2014 revision: highlights Department of Economic and Social Affairs, Population Division, United Nations.ISBN 978-92-1-151517-6.

Vogt and Oke, 2003: Vogt J.A., Oke T.R., 2003. Thermal remote sensing of urban climates, Remote Sensing of Environment, 86:370-384.

URL-1:http://www.tuik.gov.tr/PreHaberBultenleri.do?id=10736 (accessed: December, 2015)

URL-2: https://tr.wikipedia.org/wiki/\%C4\%B0zmit (accessed: December, 2015)

URL-3: http://www.izmit.gov.tr/default_B0.aspx?content=197

URL-4: http://www.mgm.gov.tr/veridegerlendirme/il-ve-ilceleristatistik.aspx?m=KOCAELI (accessed: December, 2015)

\section{URL-5: http://atmcorr.gsfc.nasa.gov/}

URL-6: http://www.solartopo.com/solar-orbit.htm(accessed: December, 2015) 